\title{
APONTAMENTOS INICIAIS SOBRE VIRILIDADE E INTELIGIBILIDADE DE GÊNEROS NA PROPOSTA DE IDENTIDADE CRISTÃ DE AGOSTINHO DE HIPONA NA PRIMEIRA IDADE MÉDIA (SÉCULOS IV E V)
}

\section{Initial notes on virility and intelligibility of genders in the proposal of christian identity of Augustine of Hipona in the first Middle Ages (centuries IV and V)}

\author{
Prof. Dr. Wendell dos Reis Veloso \\ Doutor em História pelo Programa de Pós-Graduação em História (PPHR-UFRRJ) \\ Professor Tutor Presencial do Curso de História EAD do Consórcio UNIRIO/CEDERJ/UAB \\ Pesquisador Associado ao LabQueer/UFRRJ e ao ATRIVM/UFMS \\ wendellvelo@gmail.com
}

Recebido em: 10/08/2019

Aprovado em: 20/03/2020

\begin{abstract}
Resumo : Esse artigo analisa como nas reflexões do eclesiástico católico Aurélio Agostinho (354-430), bispo da cidade africana Hipona, sobre a pessoa cristã estabelecida como padrão universal, esta acaba por se confundir com os seres entendidos como masculinos, os homens, por sua vez, diferenciados das "outras", entendidas como o específico que necessita de decodificação em um claro processo de criação social das identidades masculinas e femininas. Dá-se especial atenção ao modo como ocorre esta dinâmica, uma vez que ela é interrogada por um sistema de gênero único e diferenciado a partir de hierarquias de perfeição, o qual, por sua vez também se associa a uma concepção de corpo único. A partir do entendimento comum aos Estudos de Gênero, de que as relações sociais de poder produzem as identidades que pretendem conformar, também objetivo, portanto, refletir sobre como o discurso agostiniano ao associar pecados à determinada performatividade de gênero fazem referências explícitas apenas às devotas cristãs, construindo assim em seu vazio uma masculinidade que se pretende como padrão já que nem mesmo é alvo de reflexão. Metodologicamente me valerei de contribuições da Análise do Discurso, tal qual proposta por Dominique Maingueneau, para análise dos tratados agostinianos "Confissões" (c. 397), "Dos Bens do Matrimônio", "A Santa Virgindade" (c.401) e "A Cidade de Deus"
\end{abstract} (c.413-427).

Palavras-Chave: Estudos de Gênero; Agostinho de Hipona; Identidade Cristã; Virilidade

Abstract: This article analyzes how in the reflections of the Catholic ecclesiastical Aurelius Augustine (354-430), bishop of the African city Hippo, about the Christian person established as a universal standard, this one ends up being confused with the beings understood as masculine, men, differentiated from the "others", understood as the specific that needs decoding in a clear process of social creation of male and female identities. Special attention is given to how this dynamic occurs, as it is questioned by a unique gender system and differentiated from hierarchies of perfection, which is also associated with a single body conception. From the common understanding of Gender Studies that social power relations produce identities that they intend to conform, it is also objective, therefore, to reflect on how the Augustinian discourse in associating sins with a particular gender performativity makes explicit references only to Christian women devotees, thus building in its emptiness a masculinity that is intended as a standard since it is not even the object of reflection. Methodologically I will use contributions from Discourse Analysis, as proposed by Dominique Maingueneau, for the analysis of the Augustinian treatises "Confessions" (c. 397), "On the Goods of Marriage", "Of Holy Virginity" (c.401) and "The City of God".

Key-words: Gender Studies; Augustine of Hippo; Christian Identity; Virility 


\section{Algumas primeiras palavras}

A despeito do que se propaga, até mesmo por integrantes do atual governo nacional, que as Universidades seriam locus da deflagração iminente de um movimento de caráter revolucionário, comunista, feminista e não apenas amplamente favorável, mas também disseminador da homossexualidade, os estudos medievais ainda se caracterizariam fortemente pelo que se poderia denominar de tradicionalismo. E entendendo política como práxis na qual não se dissociam reflexão teórica e ação, só nos resta lamentar que esta seja a realidade.

Acerca disto, como sistematizado por Cassiano Celestino de Jesus e Bruno Gonçalves Alvaro, os trabalhos acadêmicos brasileiros desenvolvidos na interconexão entre os Estudos Medievais e os Estudos de Gênero entre os anos 2000 e 2015 são escassos, e, para além disso, são acanhados, com quase a sua totalidade tendo estabelecido diálogo, de modo incipiente, com as proposições do texto seminal de Joan Scott sobre o gênero ser, ou não, uma categoria útil de análise histórica (JESUS; ALVARO, 2018).

Da leitura do texto dos medievalistas brasileiros depreende-se ainda que houve uma insistente confusão entre os Estudos de Gênero e a aplicação do gênero enquanto categoria de análise, ou até mesmo falar sobre mulheres ou daqueles que seriam os elementos garantidores de mulheridade (JESUS; ALVARO, 2018).

Quero ressaltar, portanto, a não reflexão sobre algo que é capital para as explicações desenvolvidas a partir dos Estudos de Gênero, a saber, os processos históricos de construção dos gêneros. Desta feita, o objetivo deste artigo é, a partir dos Estudos de Gênero, mais especificamente a partir das proposições da filósofa estudunidense Judith Butler em sua obra Problemas de Gênero, pensar como o discurso episcopal de Aurélio Agostinho ficcionaliza uma determinada inteligibilidade de gêneros, uma vez que os mesmos não são naturais ou biológicos, a qual tensiona a noção de virilidade romana. Assim, objetiva-se contribuir para o avanço da discussão que envolvem os gêneros na área de História Medieval.

Metodologicamente me valerei de contribuições da Análise do Discurso, tal qual proposta por Dominique Maingueneau, para análise dos tratados agostinianos 
Confissões (c. 397), Dos Bens do Matrimônio, A Santa Vigindade (c. 401), e A Cidade de Deus (c.413-427). Tendo sido o último um grande tratado com vários interlocutores, entre eles pagãos e pelagianistas. Os dois antecessores foram partes de um mesmo projeto de enfrentamento das interpretações jovinianista e jeromista do cristianismo, ao passo que o primeiro tinha como principais adversários os cristãos maniqueístas.

\section{Compreendendo as inteligibilidades de gêneros na Primeira Idade Média a} partir dos Estudos de Gênero

A filósofa estadunidense Judith Butler é considerada uma das mais importantes teóricas dos Estudos Queer e de gênero. Embora sua produção seja vasta, neste artigo as reflexões se valem especificamente de sua obra seminal Gender Trouble publicada no ano de 1990, posteriormente traduzida para o português e publicada no Brasil como Problemas de Gênero.

Explicitamente tributária das reflexões de Michel Foucault, Butler já de início deixa claro que a questão do gênero não pode ser pensada alijando o poder da equação. Contudo, não apenas atesta que as diferenças entre homens e mulheres são pautadas em relações de poder, mas sim, e aí se encontra o mais frutífero do seu trabalho, que o poder cria, produz, forja, inventa estas supostas diferenças. E mais, a dinâmica empreendida por determinada tecnologia de poder estabelece aquilo que será o sujeito, a referência confundida com os homens cisgêneros, e o Outro, compulsoriamente associado às mulheres cisgêneras, além de operar nas supostas estabilidade e coerência deste sistema binário e hierárquico que se pretende não interdependente (BUTLER, 2017: 8).

Para Butler, cujo objetivo é a análise das sociedades contemporâneas, a melhor maneira de interrogar esse sistema de gênero - incluindo todos os elementos que o compõem, a saber, as concepções de corpo, de sexo, de desejo e de sexualidades -, o qual sustenta a hierarquia dos gêneros, é desmascarar o regime epistemológico da presunção da heterossexualidade. Em outras palavras, lançar luz sobre como o sistema de saber-poder-prazer cria fábulas de gêneros justificadas por meio de uma miríade de 
ficções $^{1}$ - médicas, jurídicas, religiosas, acadêmicas, das tradições familiares etc- através das quais se cristalizam as noções de mulher e de homem como um fato natural que se atrela, por sua vez, à determinadas genitálias e performatividades sociais, corpos específicos e desejos pretensamente estáveis que corresponderiam às experiências de prazer bem delimitadas (BUTLER, 2017: 7-15). Identidade heterossexualizada esta que a teórica estadunidense chama de gênero inteligível (BUTLER, 2017: 43).

Fica em xeque, portanto, o entendimento do gênero como a interpretação cultural de um corpo sexuado, o qual pressupõe o sexo binário estável de modo que os vocábulos homem e mulher fariam referências incontestes a corpos masculinos e a corpos femininos respectivamente. Nas palavras da própria Butler: "A hipótese de um sistema binário dos gêneros encerra ímplicitamente a crença numa relação mimética entre gênero e sexo, na qual o gênero reflete o sexo ou é por ele restrito" (BUTLER, 2017: 26).

Julgo importante mais um trecho da obra de Butler:

\begin{abstract}
A instituição de uma heterossexualidade compulsória e naturalizada exige e regula o gênero como uma relação binária em que o termo masculino diferencia-se do termo feminino, realizando-se essa diferenciação por meio das práticas do desejo heterossexual. $\mathrm{O}$ ato de diferenciar os dois momentos oposicionais da estrutura binária resulta numa consolidação de cada um de seus termos, da coerência interna respectiva do sexo, do gênero e do desejo (BUTLER, 2017: 53).
\end{abstract}

O incômodo, o transtorno do qual Judith Butler é a porta voz, desafia a norma estabelecida com a fértil reflexão acerca do impacto que desmascarar o esquema de construção da inteligibilidade dos gêneros causa. Sendo a metafísica dos gêneros inteligíveis uma falsa realidade abstrata - tal qual um unicórnio que sabemos como é, mas que de fato não existe - esculpida com o auxílio de diversos instrumentos discursivos ficcionais, é capital não parar na problematização da suposta coerência da

\footnotetext{
${ }^{1}$ Ressalto que não estou me referindo à noção do senso comum sobre ficção, a qual associa este vocábulo à mentira ou à encenação. Como bem ressaltou Foucault: "Quanto ao problema da ficção, para mim é um problema muito importante; tenho consciência de que sempre escrevi somente ficções. Nem por isso quero dizer que isso esteja fora da verdade, de induzir efeitos de verdade com um discurso de ficção, e provocar, de algum modo, que o discurso de verdade suscite, fabrique alguma coisa que ainda não existe, que, então, 'ficcione'. 'Ficciona-se' história a partir de uma realidade política que a torna verdadeira; 'ficciona-se' uma política que não existe ainda a partir de uma verdade histórica” (FOUCAULT, 2014: 43).
} 
matriz heteronormativa e seguir interrogando os próprios constructos que nós chamamos de sexo e de gênero.

Desta maneira, questiona-se se o sexo não foi sempre gênero, pois o entendimento daquele em sua forma dual e antagônica só é possível em um sistema de gênero igualmente duplo e hierárquico, o que impossibilita a compreensão do gênero como a significação cultural de corpos sexuados. A implosão não apenas da relação supostamente coesa entre corpo e gênero, mas também do que são os próprios gêneros e os corpos autoriza que uma miríade de corpos se enquadre em um determinado marcador de gênero, assim como enseja uma performatividade de gênero descentralizada (BUTLER, 2017: 26-30).

Todas essas discussões, as quais não podem ser ignoradas ao se discutir as questões de gênero, evidenciam que não me apoio na concepção surgida ao longo das décadas de 1960/70 em que falar de gênero era necessariamente falar de mulheres. Atualmente, todos estes debates, incluindo os estudos sobre as mulheres e sobre os queer, são enquadrados nos Estudos de Gênero, nos quais o gênero pode ser tomado como mais do que uma categoria aplicável à análise e funciona como um posicionamento epistemológico, uma perspectiva que pode ser articulada a uma vasta gama de temáticas e discussões teórico-metodológicas (SILVA, 2016: 153-157).

Para Fernando Balieiro os Estudos de Gênero podem ser especialmente caracterizados por "considerar os amplos aspectos históricos e sociais que moldam as relações afetivo-sexuais nos contextos contemporâneos, colocando relevo na construção discursiva da sexualidade bem como de gênero" (BALIEIRO, 2015: 29).

Logo, toma-se como pressuposto que o gênero é anterior aos sexos naturalizados. Hodiernamente a matriz heterossexual se ampara em uma concepção de corpos duais e antagônicos que se pretende anterior, mas é posterior à concepção de gênero igualmente dual e antagônica. E na Primeira Idade Média, como seria?

Em 1990 Thomas Laqueur publicou aquela que ainda hoje é a referência no estudo sobre as concepções dos corpos e dos gêneros no Ocidente em uma larga envergadura temporal. O historiador e sexólogo estadunidense argumenta que entre o século II EC e o século XVIII EC vigorou no pensamento ocidental a teoria do corpo único. 
De acordo com este autor, o médico-filósofo Claudius Galenus desenvolveu no II século de nossa Era o princípio de que os seres que nós designamos homens e mulheres são essencialmente iguais, mas também são diferentes. Iguais em fundamento, mas diferentes em qualidade. Na verdade, haveria apenas os homens, aqueles perfeitos, os quais nós traduzimos como homens, e os imperfeitos, posto que não teriam recebido calor vital para se desenvolverem quando no útero, os quais traduzimos como mulheres. É por esse motivo que os órgãos característicos das mulheres são internos enquanto os dos homens são à vista, defendia. Por exemplo, Galeno se referia como testículos ao que hoje chamamos ovários (LAQUEUR, 2001: 23), cuja existência em determinados corpos é uma das tecnologias de poder contemporâneas para definir a mulheridade dos seres e excluir desta dinâmica as transmulheres (LAQUEUR, 2001: 16).

A existência de sexos opostos teria surgido apenas no século XVIII no mesmo bojo em que as mulheres passaram a ser entendidas como completamente diferentes dos homens nos aspectos morais e físicos. A relação da mulher e do homem se dá, a partir de então, através de oposições e contrastes (LAQUEUR, 2001: 17). Em palavras do próprio Laqueur:

(...), o antigo modelo no qual homens e mulheres eram classificados conforme seu grau de perfeição metafísica, seu calor vital, ao longo de um eixo cuja causa final era masculina, deu lugar, no final do século XVIII, a um novo modelo de dismorfismo radical, de divergência biológica. Uma anatomia e fisiologia de incomensuralidade substituiu uma metafísica de hierarquia na representação da mulher com relação ao homem (LAQUEUR, 2001: 17).

Seguindo com as reflexões o autor faz instigante proposta. Reafirmando que no Ocidente pré-Iluminismo o que nós denominamos de sexo e de gênero atualmente só eram possíveis em um modelo de corpo único, Laqueur sugere que - contrariamente ao binarismo corpo-natureza versus gênero-cultura nos quais ainda hoje há quem acredite - o gênero era o que se entendia como real e o corpo, ou o sexo, era uma espécie de epifenômeno, era uma convenção (LAQUEUR, 2001: 19).

Dito de outra forma: 
Ser homem ou ser mulher era manter uma posição social, um lugar na sociedade, assumir um papel cultural, não ser organicamente um ou outro de dois sexos incomensuráveis. Em outras palavras, o sexo antes do século XVII era ainda uma categoria sociológica e não ontológica (LAQUEUR, 2001: 19).

Fica evidente que a inteligibilidade dos gêneros na Primeira Idade Média não ocorre em uma estrutura heteronormativa. Cabe então refletirmos sobre em qual estrutura se dariam estes gêneros. O posicionamento social que era ser homem ocorria em uma estrutura masculinista e falocêntrica na qual o pênis seria o símbolo da perfeição alcançada no ventre materno, de modo que os seres imperfeitos já sairiam perdendo na corrida pela virilitas. É desta justificativa que se se parte para a relação entre a cidadania, o gozo do espaço público, e os corpos masculinos entendidos como perfeitos, excluindo assim as mulheres. Acerca disto, Greg Woolf ressalta que, embora os romanos historicamente se valessem da cidadania de modos diferentes na dinamização do seu espaço público uma coisa se manteve constante. A saber, que entre todos os atributos definidores do cidadão romano, nenhum seria aplicável às mulheres (WOOLF, 2017: 284).

No entanto, este corpo alegadamente perfeito não seria garantidor do que poderíamos chamar de masculinidade, posto que deveria vir acompanhado de uma determinada performatividade, um comportamento, a virilidade. Esta virilitas romana deve ser entendida como virtude, a qual deveria acompanhar os seres concluídos, os homens (VIGARELLO, 2013: 11), mas que não era condição destes.

A alusão feita anteriormente à importância do falo se dá pela centralidade que a penetração possui na definição do homem romano, o vir (VEYNE, 1990, 2008; SCHULTZ, 2006; THUILLIER, 2013), o qual seria basicamente um penetrador (THUILLIER, 2013: 74), um violador de corpos inacabados. Deste modo, um menino, o puer, somente se tornaria um vir após a sua primeira experiência sexual feminina (THUILLIER, 2013: 76), na qual ele certamente teria que atuar como o penetrador, em outras palavras, o vir seria aquele que estoca e nunca o estocado (THUILLIER, 2013: $82-90)$.

Não cabe aqui nos debruçarmos sobre a diferença entre estas prescrições que constituiriam os mos maiorum romano e a vida vivida, com a leniência característica desta última (FEITOSA, 2016), nem mesmo sobre a diferença entre práticas eróticas 
conscientes e processos históricos de subjetivação através da sexualidade (HALPERIN, 2000; SCHULTZ, 2006; VELOSO, 2019), mas sim destacar que práticas sexuais voltadas para o prazer do homem adulto são constituintes da virilitas e, portanto, são também estruturantes da cidadania romana.

Essa inteligibilidade de gêneros pautada em uma hierarquia de perfeição que pressupõe o uso daquele considerado inferior, posto que inacabado e, portanto, imperfeito, para o seu prazer sexual tem que se coadunar, ao menos em seus discursos institucionais, à realidade da aproximação entre as estruturas formais do Império Romano e a facção católica do cristianismo em fins do século IV. E quando ocorre a cristianização protocolar do Império e se afirma como legítimos partícipes da ecclesia aqueles que aceitassem como verdadeira a definição cristológica proposta pelos poderes formais já cristianizados (The Codex Theodosianus: on Religion, $4^{\text {th }}$ Century CE), a cidadania somente se torna possível via Igreja - o conjunto de igrejas locais entendidas como ortodoxas, católicas. É este elemento dinamizador das instituições formais de poder cristianizadas que abordarei. Como já colocado, a partir do decreto de Teodósio declarando o cristianismo a religião do Império, assim como a obrigatoriedade de seguíla, ser romano só se torna possível se também cristão. E embora a cidadania e o espaço público romano sejam apanágios dos seres identificados com o masculino as mulheres também podem ser cristãs e, portanto, integrantes da ecclesia. Logo, será que esta nova dinâmica causou alguma fissura nas estruturas de poder?

A partir da leitura da historiografia depreende-se que o cristianismo poderia, inclusive, ser uma estratégia para certa independência feminina, tal qual defende Joyce Salisbury em Pais da Igreja, Virgens Independentes (1995). Contudo, como demonstram Elizabeth Clark (1989), Regina Bustamante (1990) e Fabiano Coelho (2018), essa independência sempre necessita da tutela masculina, inclusive a cristandade dessas mulheres, ao menos de modo institucional, precisa sempre da confirmação de um poder masculino.

Outro elemento de tensão entre a inteligibilidade de gêneros tradicional romana e a proposta de identidade cristã agostiniana é a virilidade ancorada na prática sexual, posto que o discurso cristão católico tende à castidade, o que ainda é potencializado no que eu denomino de discurso agostiniano (VELOSO, 2018) entendido em toda a sua complexidade (VELOSO, 2015, 2016). 
É tendo em vista estas considerações teóricas que identifico e analiso o modo como Aurélio Agostinho propôs a sua versão cristã da inteligibilidade de gêneros.

\section{As referências no discurso agostiniano}

Entendo que os tratados agostinianos que analiso constituem o discurso agostiniano, um espaço discursivo heterogêneo, mas com elementos comuns (MAINGUENEAU, 2008: 35) no qual uma determinada inteligibilidade de gênero é ficcionalizada a partir de dispositivos discursivos, uma vez que estes textos podem ser entendidos como estratégias de poder, como relações de força que se amparam e também sustentam tipos de saber (FOUCAULT, 2007: 248), como a interpretação cristã sobre os corpos.

Aurélio Agostinho (354-430) foi um pensador ligado ao credo cristão niceno, nascido na província africana do Império Romano exerceu o cargo episcopal na cidade de Hipona. Entre um de seus maiores escritos está Confissões (Confessiones). Escrita por volta de 397 esta obra tem caráter autobiográfico e, portanto, propicia a reflexão sobre diversos assuntos por cobrir um vasto período de tempo da vida do biografado. Entres os assuntos tratados certamente se encontram os de interesse deste artigo, de maneira direta ou inferidos de modo indiciário. Nesta obra o já bispo de Hipona narra os desejos sexuais que o perturbavam durante a adolescência e como a demora em cometer apostasia ao cristianismo maniqueu se deu também pelo receio em adotar uma vida de castidade, o que é apresentado por ele como sinônimo de adoção do cristianismo católico, associação esta fundamental para as reflexões empreendidas aqui por contrariar o cerne da noção de virilitas romana.

Em Confissões há reflexões sobre a amizade que nos interessam:

Era para mim mais doce amar e ser amado, se podia gozar do corpo da pessoa amada. Deste modo, manchava, com torpe concupiscência, aquela fonte de amizade. Embaciava a sua pureza com o fumo infernal da luxúria (AGOSTINHO, Confessiones, I, III, I). 
Percebe-se através do trecho acima a importância do prazer sexual para Agostinho, visto que o autor descreve que, para ele, seria mais regozijante amar quando houvesse a possibilidade de usufruir do corpo de quem se ama. Em seguida, o pensador claramente afirma que esta concuspicência que o levava a desejar o corpo do objeto de seu amor seria também o elemento desordenador de um outro amor, o qual ele descreve como puro, e que, por inferência, pode-se entender como o amor ideal, o amor entre amigos.

Um pouco antes, ao relatar episódios de sua adolescência, tema de todo o segundo livro, Agostinho mais uma vez aborda a amizade como um tipo de amor que se mostra antagônico ao amor sexuado:

\begin{abstract}
Que coisa me deleitava senão amar e ser amado? Mas, nas relações de alma para alma, não me continha a moderação, conforme o limite luminoso da amizade, visto que, da lodosa concupiscência da minha carne e do borbulhar da juventude, exalavam-se vapores que me enevoavam e ofuscavam o coração, a ponto de não se distinguir o amor sereno do prazer tenebroso. Um e outro ardiam confusamente em mim (AGOSTINHO, Confessiones, I, II, II).
\end{abstract}

O trecho coloca em destaque a amizade como demarcador de uma relação social e íntima saudável entre duas pessoas. Este ponto limítrofe, entre o que o hiponense denomina de "amor sereno" ("serenitas dilectionis") e de "prazer tenebroso" (caligine libidinis), o que ainda poderia ser traduzido como prazer impuro, ficaria de difícil precisão devido ao que o bispo denomina de "lodosa concupiscência da minha carne" e do "borbulhar da juventude", o que se pode entender como a libido comumente associada a este período da vida humana, como narra o próprio Agostinho em trecho posterior (AGOSTINHO, Confessiones, I, II, III).

Pode-se atestar o tom negativo associado aos atos sexuais, assim como aos impulsos e aos desejos que o potencializam, aproximando assim o pensamento do hiponense das proposições maniqueístas, corrente cristã bastante austera no que tange à prática sexual.

Há ainda uma outra seção de Confissões em que o eclesiástico comenta sobre os seus planos e os de Alípio, um de seus melhores amigos, para viverem juntos e em castidade no que descreve como um ambiente de segura tranquilidade e no amor da 
sabedoria. Planos estes colocados em xeque pelo aventamento de um casamento para Agostinho, fato este ao qual, segundo o próprio, Alípio colocou-se em oposição (AGOSTINHO, Confessiones, I, VI, XII).

Isto se deu, pois, após a sua conversão, a qual segundo Peter Brown deve ser entendida como uma experiência grupal, Agostinho e seus amigos colocaram em prática o projeto de levar uma vida comum e em abstinência (BROWN, 1990: 325). No livro de suas confissões, em trecho no qual aborda o seu batismo, é possível reconhecer isto:

\begin{abstract}
"Vós que fazeis com que os unânimes habitem na mesma morada", associastes a nós o jovem Evódio, natural do nosso município. Era agente de negócios do Imperador e, tendo-se convertido e batizado antes de nós, renunciou às milícias profanas, alistando-se na vossa. Estávamos juntos, queríamos habitar em comum num convívio santo (AGOSTINHO, Confessiones, I, IX, VIII).
\end{abstract}

Embora eu já tenha feito referência a isto a partir da análise documental, a historiografia ajuda no exercício de compreensão. Peter Brown sustenta que no contexto da Primeira Idade Média, no século IV, a amizade entre dois homens seria a mais profunda forma de duas pessoas relacionarem-se (BROWN, 1990: 320). Há ainda um outro trecho de Confissões no qual, o já bispo da região de Hipona, caracteriza este tipo de relação fraternal ao discorrer sobre o que mais o alegrava no trato com seus amigos:

\footnotetext{
Havia neles outros prazeres que me seduziam ainda o coração: conversar e rir, prestar obséquios com amabilidade uns aos outros, ler em comum livros deleitosos, gracejar, honrar-se mutuamente, discordar de tempos a tempos sem ódio como cada um consigo mesmo e, por meio desta discórdia raríssima, afirmar a contínua harmonia, ensinar ou aprender reciprocamente qualquer coisa, ter saudade dos ausentes e receber com alegria os recém-vindos. Destes e semelhantes sinais, que, procedendo do coração dos que se amam e dos que pagam amor com amor, manifestam-se no rosto, na língua, nos olhos e em mil gestos cheios de prazer, como se fossem gravetos, inflamam-se os corações e de muitos destes se vem a formar um só (AGOSTINHO, Confessiones, I, IV, VIII).
}

Fica estabelecida a profundidade da relação que deveria haver entre dois amigos no trecho em que é afirmado textualmente que, para além da vida cotidiana compartilhada, os corações dos amigos deveriam tornar-se um só. Outro ponto que deve 
ser assinalado é a busca por conhecimento como parte constituidora dos objetivos deste tipo de relação, pois deveriam "ler em comum livros deleitosos" e "ensinar ou aprender reciprocamente qualquer coisa." Outro fator de extrema importância a ser demonstrado neste trecho é a igualdade como pressuposto das relações de amizade, o que se antagoniza à concepção de gênero hierárquica do período, de acordo com a qual as mulheres ocupam a elemento inferior desta hierarquia, uma vez que seriam seres inacabados.

No capítulo dedicado à sedução dos olhos Agostinho de Hipona conecta o alegado pecado da visão, uma característica fisiológica da maioria dos seres humanos, a alguns aspectos do cotidiano.

\footnotetext{
Que multidão inumerável de encantos não acrescentaram os homens às seduções da vista, com a variedade das artes, com as indústrias de vestidos, calçados, vasos, com outros fabricos desta espécie, com pinturas e esculturas variadas, com que ultrapassam o uso necessário moderado e a piedosa representação dos objetos! No exterior correm atrás das suas obras. No interior esquecem Aquele que os criou e destroem o que por meio dele fizeram (AGOSTINHO, Confessiones, II, X, XXXIV).
}

O bispo de Hipona estabelece as mais variadas artes, as vestes e os calçados como instrumentos de sedução da vista. Tais elementos listados pelo hiponense não deveriam ter os seus usos estirados para além do necessário. Atentando para o fim do parágrafo transcrito pode-se verificar o autor argumentar que o uso de tais coisas deveria refletir o interior, uma vez que ele condena aqueles que apegam-se demais às obras, mais do que aquele que supostamente as teria criado, o deus dos cristãos.

Este padrão também aparece nos tratados Dos Bens do Matrimônio (De Bono Coniugalli) e A Santa Virgindade (De Sancta Virginitate). Estes foram escritos na primeira década do $\mathrm{V}$ século e tratam da defesa da identidade católica em meio a uma discussão entre o monge Jerônimo, o bispo Agostinho e o monge Joviniano, e que tem como ponto central as sexualidades. Neste tratado o pecado ligado à frivolidade não é apenas censurado para os cristãos, para além disso, ele é associado explicitamente ao feminino. O bispo afirma que de nada adiantaria a mulher evitar o casamento a fim de manter-se casta, mas não evitar os cabelos frisados, as joias de ouro, as pérolas e os vestidos elegantes. Neste mesmo fragmento as mulheres ainda são descritas como 
luxuriosas, orgulhosas, fofoqueiras e tagarelas (AGOSTINHO, De Bono Coniugalli, XII, 14). Já no tratado subsequente, fruto de um mesmo projeto, as mulheres são colocadas sob os epítetos degenerativos de indiscretas, faladeiras, ociosas e desocupadas (AGOSTINHO, De Sancta Virginitate, XXXIII, 34).

Podemos seguir nesse acúmulo de informações com um excerto de $A$ Cidade de Deus (De Civitate Dei), esta, considerada a grande obra agostiniana. De dimensão monumental o tratado aborda diversos temas e tem como um dos seus pontos de partida a defesa do catolicismo ante ao que talvez se organizasse como uma nova frente pagã no Império, assim como a defesa frente ao pelagianismo e sua exegese do mito criacionista. Neste, o hiponense afirmou:

Não temos a menor dúvida de que o crescer, multiplicar-se e povoar a terra, segundo a benção de Deus, é dom do matrimônio, instituído por Deus, desde o princípio, antes do pecado, ao criar o homem e a mulher. $\mathrm{O}$ sexo, evidentemente, supõe algo carnal. E a essa obra de Deus seguiu-se imediatamente sua benção. Em havendo dito a Escritura: Fê-los homem e mulher, logo acrescentou: a terra e dominai-a, etc. Embora a tudo isso seja possível dar-se interpretação espiritual não incongruente, as palavras homem $e$ mulher não podem ser entendidas como algo existente em apenas um sujeito, pretextando ser nele uma coisa a que governa e outra a governada. Como de maneira muito clara se vê nos corpos de seres de sexo diferente, o homem e a mulher foram criados com o fim de que, pela geração da prole, crescessem, se multiplicassem e povoassem a terra. Se refratário a isso constituiria notável absurdo (AGOSTINHO, De Civitate Dei, XVI, XXII).

No início é afirmado que o imperativo da procriação é anterior ao Pecado Original. E contra as interpretações espirituais do mito, ele declara que o sexo, obviamente, supõe algo carnal. A isto se segue afirmação talhada perfeitamente para exemplificar uma das máximas dos Estudos de Gênero, a saber, que o gênero é um dos elementos mais primários que estruturam as relações de poder. Agostinho de Hipona associa de modo explícito o homem ao governo e à mulher ao que é governado, em mais um exemplo de sua flagrante misoginia, comum à época, mas de cores bastante acentuadas em seu pensamento.

Pode-se agora retomar as análises a fim de sistematizá-las. 


\section{Conclusão}

A concepção agostiniana de amizade, caracterizada por ele como uma relação de igualdade em que um aprenderia com o outro, antagoniza-se à concepção de Agostinho para o matrimônio, visto que este somente poderia ocorrer entre masculi et feminae e a interação entre estes deve ser pautada por uma hierarquia na qual o homem governa a mulher.

Outro ponto crucial é a insistência em que o deus cristão teria criado "masculi et feminae" "Masculum et feminam". A ligação contundente dos seres socialmente designados homens e mulheres às suas características de macho e fêmea apontam para a procriação como o elemento moralizador do sexo. Entretanto, pode também lançar um feixe de luz na formulação de outra questão, ainda que para ela este texto não forneça respostas. Considerando o campo discursivo formado pelos textos agostinianos é possível visualizar o estabelecimento, ou parte importante dele, do pênis e da vagina como órgãos essencialmente reprodutores?

Essa questão é importante, pois, esta cristalização termina em uma concepção de gênero estável e, sobretudo, de um sexo, entendido como natureza também estável, o que não era o comum neste período. No Império Romano se encontram muitos exemplos de que as performatividades dos gêneros masculino e feminino não estariam irremediavelmente associadas à condição de macho e de fêmea respectivamente. Dos sacerdotes/sacerdotisas de Cibele (PINTO, PINTO, 2014); passando pela vida amorosa de generais dos exércitos romanos (CAMPOS, 2019), até imperadores que se casaram, vestidos de noiva, com seus amantes (ESTEVES, 2017) ou que demandaram ser tratados por senhora e não por senhor (CORSI SILVA, 2018). E no trecho documental, como se verifica, há o argumento de que o masculino e o feminino não poderiam ocupar o mesmo corpo.

A concepção de amizade assexuada entre iguais se conflita com a inteligibilidade de gêneros não cristã, embora se relacione com esta. A performatividade de gênero do vir cristão, a prática social de gênero que se esperava do macho cristão, seria caracterizada pela castidade e pelo afastamento de todo o excesso, como se verifica no trecho em que ele comenta os supostos pecados da visão. Deve-se salientar que ao cristão se recomenda o afastamento do excesso, como quem deveria evitar algo que lhe 
é, de certa forma, externo, já às cristãs a recomendação vem acompanhada de acusação que funciona discursivamente como uma constatação, a de que elas seriam dadas às frivolidades, ao excesso.

Trata-se do que Dominique Maingueneau chamou de "caráter essencialmente dialógico de todo enunciado do discurso", , ressaltando que o outro em um determinado campo discursivo circunscreve-se no vazio do discurso que se pretende referência. Neste caso, evidencia-se o negativo para construir em seu vazio o positivo, associado ao homem cristão.

Ainda sobre o outro, nas palavras de Maingueneau:

\begin{abstract}
Ele se encontra na raiz de um Mesmo sempre já descentrado em relação a si próprio, que não é em momento algum passível de ser considerado sob a figura de uma plenitude autônoma. Ele é aquele que faz sistematicamente falta a um discurso e lhe permite encerrar-se em um todo. É aquela parte de sentido que foi necessário o discurso sacrificar para constituir a própria identidade (MAINGUENEAU, 2007: 37).
\end{abstract}

Em outras palavras, em um contexto no qual a cidadania romana só é possível através do cristianismo católico, os homens, os cidadãos por excelência em toda a História do Império Romano, declaram-se melhores cristãos do que as mulheres. Estas, ao que parece, por uma questão que hoje nós caracterizaríamos como congênita, estariam mais distantes do deus cristão. Talvez porque além da distração que lhes teria sido imposta alegadamente pela biologia - a procriação, o monopólio da criação dos filhos e a incapacidade intelectual - também são associadas discursivamente a tudo o que é considerado frívolo e volátil, distrações que as impediriam de se dedicar com intensidade ao retorno à imago dei.

Estas descrições agostinianas funcionam como instrumentos discursivos que esculpem uma determinada inteligibilidade de gêneros. Antes organizada em níveis de perfeição que se associavam à virilitas, ou à falta dela, de modo que o cidadão, o vir completo/perfeito, demonstraria sua virilitas por meio da tomada do sexo daqueles considerados incompletos/imperfeitos; a inteligibilidade de gêneros proposta por Agostinho ficcionaliza uma identidade cristã majoritariamente masculina, de acordo

\footnotetext{
${ }^{2} \mathrm{O}$ itálico encontra-se no texto.
} 
com a qual o vir deveria demonstrar a sua continência, não apenas sexual, mas em todos os aspectos de seu cotidiano, ao passo que também parece apontar para um processo histórico que outorgaria uma espécie de fatalismo aos corpos cada vez mais associados de modo rígido a determinadas performatividades de gênero.

Ou seja, estaríamos diante do processo histórico de criação do gênero como mais do que uma virtude, e sim como uma substância, um elemento estável? Isto ainda está por se investigar, contudo, se antes os corpos imperfeitos poderiam, ainda que não fosse fácil e nem de modo completo, aproximar-se do valor que era a virilitas, Agostinho parece ter dificultado ainda mais a situação das mulheres ao sugerir que o seu estado de imperfeição fosse, na verdade, uma condição.

\section{Bibliografia:}

\section{Fontes Documentais:}

AgOSTINHO, Santo. A Cidade de Deus: Contra os Pagãos. $8^{a}$ ed. Tradução de Oscar Paes Leme. Bragança Paulista: Editora Universitária São Francisco, 2008. (Coleção Pensamento Humano). 2 v.

AgOSTINHO, Santo. A Santa Virgindade. $2^{\mathrm{a}}$ ed. Tradução de Nair de Assis Oliveira. São Paulo: Paulus, 2007a.

AGOSTINHO, Santo. Confissões. Tradução de J. Oliveira e A. Ambrosio de Pina. Petrópolis, Rio de Janeiro: Vozes, 2011.

AGOSTINHO, Santo. Dos Bens do Matrimônio. $2^{\mathrm{a}}$ ed. Tradução de Vicente Rabanal. São Paulo: Paulus, 2007b.

AGUSTIN, San. La Bondad del Matrimonio. In: Obras de San Agustin. Texto Bilingüe. Madrid: La Editorial Católica, 2007a. (Biblioteca de Autores Cristianos, Tomo XII)

AGUSTIN, San. La Santa Virginidad. In: Obras de San Agustin. Texto Bilingüe. Madrid: La Editorial Católica, 2007b. (Biblioteca de Autores Cristianos, Tomo XII)

AUGUSTINUS, Aurelius. Confessiones. In: Obras de San Agustin. Texto Bilingüe. Madrid: La Editorial Católica, 1963. (Biblioteca de Autores Cristianos, Tomo II)

AUGUSTINUS, Aurelius. De Bono Coniugalli. In: Obras de San Agustin. Texto Bilingüe. Madrid: La Editorial Católica, 2007a.

AUGUSTINUS, Aurelius. De Sancta Virginitate. In: Obras de San Agustin. Texto Bilingüe. Madrid: La Editorial Católica, 2007b. 
The Codex Theodosianus: on Religion, $4^{\text {th }}$ Century CE. In: Documenta Catholica Omnia. Disponível em: http://www.documentacatholicaomnia.eu/10_10_0438-0438_Codex_Theodosianus.html. Acesso em fevereiro de 2011.

\section{Textos Teóricos e Historiográficos}

BALIEIRO, Fernando de Figueiredo. Introdução. In: - A Pedagogia do Sexo em o Ateneu: Gênero e Sexualidade no Internato da "Fina Flor da Sociedade Brasileira." São Paulo: Annablume, 2015, pp. 23-34.

BROWN, Peter. Corpo e Sociedade: o Homem, a Mulher e a Renúncia Sexual no Início do Cristianismo. Rio de Janeiro: Jorge Zahar, 1990.

BUSTAMANTE, Regina Maria da Cunha. O Casamento e a Esposa: A Visão de Agostinho de Hipona. Tese (Mestrado em História Social), Universidade Federal do Rio de Janeiro, Instituto de Filosofia e Ciências Sociais, Rio de Janeiro, 1990.

BUTLER, Judith P. Problemas de Gênero: feminismo e subversão da identidade. 14 ed. Rio de Janeiro: Civilização Brasileira, 2017.

CAMPOS, Carlos Eduardo da Costa. A masculinidade de Otaviano sob ataque: relações de poder e potencialidade para liderança de Roma, no século I AEC. Revista de História da Unisinos, 2019. (Artigo no prelo)

CLARK, Elizabeth Ann. Theory and Practice in Late Ancient Ascetism: Jerome, Chrysostom, and Augustine. Journal of Feminist Studies in Religion 2 (5), 1989, p. $25-46$.

COELHO, Fabiano de Souza. As Matronas na Antiguidade Cristã: um estudo comparado das representações de gênero nas obras de Jerônimo e Agostinho (390420 EC). 317 páginas. (Doutorado em História Comparada) Instituto de História PPGHC, Universidade Federal do Rio de Janeiro, RJ, 2018.

CORSI SILVA, Semíramis. Identidade Cultural e Gênero no Principado Romano: Uma Proposta de Análise Interseccional das Representações do Imperador Heliogábalo (Século III E.C.). Phoînix (24), 2018, p. 142-166.

ESTEVES, Anderson de Araújo Martins. Nero e o paradigma priápico: a construção de uma identidade. Conferência de Abertura proferida dia 29/05/2017 na IV Jornada de Estudos do GEMAM/UFSM. Prazeres Antigos: Comer, Jogar e Amar na Antiguidade.

FEITOSA, Lourdes Conde. O Amor entre iguais: o Universo Masculino na Sociedade Romana. In: ESTEVES, Anderson Martins; AZEVEDO, Katia Teonia; FROHWEIN, Fábio (orgs.). O Homoerotismo na Antiguidade Clássica. 2. ed. Rio de Janeiro: UFRJ, 2016, pp. 124-140.

FOUCAULT, Michel. As Relações de Poder Passam para o Interior dos Corpos. In: Ditos e escritos, volume IX: genealogia da ética, subjetividade e sexualidade. Org., seleção e revisão técnica Manoel Barros da Motta. Tradução Abner Chiquieri. Rio de Janeiro: Forense Universitária, 2014, pp 35-43. 
FOUCAULT, Michel. Sobre a História da Sexualidade. In: . Microfísica do Poder. Organização e tradução Roberto Machado. 23 ${ }^{\mathrm{a}}$ ed. Rio de Janeiro: Edições Graal, 2007, pp. 243-276.

HALPERIN, David M. How To Do the History of Homosexuality. GLQ: A Journal of Lesbian and Gay Studies 1 (6), 2000, p. 87-123.

JESUS, Cassiano Ceslestino; ALVARO, Bruno Gonçalves . (Des)problematizando a Idade Média: Reflexões Sobre a Perspectiva do Gênero na Medievística Brasileira (2000-2015). EXPEDIÇÕES: TEORIA DA HISTÓRIA E HISTORIOGRAFIA (9), 2018, p. 17-35.

LAQUEUR, Thomas. Inventando o sexo: Corpo e Gênero dos Gregos a Freud. Rio de Janeiro: Relume Dumará, 2001.

MAINGUENEAU, Dominique. Gênese dos discursos. Tradução Sírio Possenti. São Paulo: Parábula editorial, 2008.

PINTO, R.; PINTO, L. C. G. Corpos Emasculados, Corpos Sagrados: dos sacerdotes de Cibele ao "travesti" de Catterick. In: Flávia Regina Marqueti; Pedro Paulo Abreu Funari. (Org.). Corpo a corpo: representações antigas e modernas da figura humana. 1ed. São Paulo: Editora Unifesp, 2014, v. 1, pp. 111-133.

SALISBURY, Joyce E. Pais da Igreja, Virgens Independentes. São Paulo: Página Aberta, 1995.

SCHULTZ, James A. Heterosexuality as a Threat to Medieval Studies. Journal of the History of Sexuality 1 (15), 2006, p. 14-29.

VEYNE, Paul. Sexo e poder em Roma. Rio de Janeiro: Civilização Brasileira, 2008.

VEYNE, Paul. A Sociedade Romana. Lisboa: Edições 70, 1990.

VIGARELLO, Georges. Introdução. A Virilidade, da Antiguidade à Modernidade. In: VIGARELLO, Georges. História da Virilidade. Vol. 1. Petrópolis, RJ: Vozes, 2013, pp. 11-16.

SILVA, Natanael de Freitas. O conceito de gênero em Scott, Butler e Preciado, aproximações, distanciamentos e a contribuição para o ofício do historiador. Revista Homium, v. 5, p. 153-171, 2016.

THUILLIER, Jean-Paul. Virilidades Romanas: Vir, virilitas e virtus. In: VIGARELlO, Georges (Org.). História da Virilidade. Vol. 1. Petrópolis, RJ: Vozes, 2013, pp. 73-124.

VELOSO, Wendell dos Reis. As Sexualidades no Pensamento Agostiniano a partir das Contribuições de Michel Foucault e Quentin Robert Skinner: Reflexões sobre a Prática Historiográfica. Roda da Fortuna. Revista Eletrônica sobre Antiguidade e Medievo (5), 2016, p. 226-245.

VELOSO, Wendell dos Reis. 'Continentes' ou 'conjugati'? Uma análise do dispositivo de sexualidade agostiniano no contexto da Querela Jovinianista. Romanitas

- Revista de Estudos Grecolatinos (11), 2018, p. 133-152.

VELOSO, Wendell dos Reis. Problematizando a Noção Historiográfica de Revolução Sexual Agostiniana: O 'Cativeiro' do Sexo e do Matrimônio em Oposição à 
'Libertação' Promovida pela Castidade no Discurso Patrístico do Século IV. Nearco (1), 2015, p. 173-194.

WOOLF, Greg. Roma: a História de um Império. Tradução Mário Molina. São Paulo: Editora Cultrix, 2017. 